Check for updates

Cite this: RSC Adv., 2017, 7, 30632

Received 7th May 2017

Accepted 6th June 2017

DOI: 10.1039/c7ra05142e

rsc.li/rsc-advances

\section{Sol-gel synthesis of nanosilica-coated para-aramid fibers and their application in the preparation of paper-based friction materials}

\author{
Zhaoqing Lu, ${ }^{\text {ab }}$ Wenjing Hu, ${ }^{a}$ Fan Xie, (D) *a Longhai Zhuo ${ }^{c}$ and Bin Yang ${ }^{a}$
}

A facile method of surface modification to fabricate nanosilica-coated aramid fibers via sol-gel process was studied and their application in the preparation of paper-based friction materials by wet-forming process was also investigated. SEM and EDS results showed that a dense coating of $\mathrm{SiO}_{2}$ nanoparticles was well established on the surface of aramid chopped fibers (ACFs). FT-IR characterization confirmed the formation of $\mathrm{Si}-\mathrm{O}-\mathrm{C}$ chemical bonds between $\mathrm{SiO}_{2}$ and ACFs. In comparison with the control sample (paper-based friction material containing pristine ACFs), the dynamic friction coefficient of the modified sample (paper-based friction material containing modified ACFs) gradually reached a steady state as a function of time. The wear rate of the modified sample was lower $(30 \%)$ than that of the control sample. The SEM micrographs of worn surfaces supported the notion that the degree of wear of the control sample was more serious compared to the modified sample. It was concluded that the nanosilica-coated ACF-containing friction materials had excellent friction properties and wear resistance.

\section{Introduction}

Paper-based friction materials are widely used for oil-immersed clutches and lock-up mechanisms in automatic transmissions. Friction materials should maintain a stable friction coefficient, low wear rate and good wear resistance during the friction process. Therein, the reinforced fibers play a critical role in the mechanical strength and friction performance of paper-based friction materials. Cellulose fibers and asbestos were commonly used as reinforcement for preferable friction performance, though these have been restricted due to the comparatively low load-carrying capacity of cellulose fiber and health problems of asbestos fibers. ${ }^{1}$ Hence, synthetic fibers were gradually developed as reinforcement in paper-based friction materials to adapt to unusual working conditions such as high temperature and high load. Aramid fiber has become an attractive high-performance synthetic fiber, which exhibits high specific strength, specific modulus, excellent heat resistance and dielectric performance. ${ }^{2-4}$ It is widely used in rail transit, automotive, aerospace, military and other high-tech areas due to its outstanding properties, which plays an important role in the modern industry field and arises great interest of many

${ }^{a}$ College of Bioresources Chemical and Materials Engineering, Shaanxi University of Science \& Technology, Xi'an, 710021, China. E-mail: xiefan198903@163.com; Tel: +86-187-9241-0639

${ }^{b}$ State Key Laboratory of Pulp and Paper Engineering, South China University of Technology, Guangzhou, 510640, China

${ }^{c}$ Collaborative Innovation Center of Chemical and Technology for Light Chemical Additives, Shaanxi University of Science \& Technology, Xi'an, 710021, China researchers. ${ }^{5,6}$ However, the application of aramid chopped fiber (ACF) in paper-based composite material has been restricted because of poor interfacial adhesion between fiber and matrix resulting from its smooth and chemically inert surface. ${ }^{7,8}$

Many studies have been reported on the surface modification of ACF, like chemical and physical treatment, ${ }^{9-11}$ plasma treatment $^{12,13}$ ultrasonic treatment, ${ }^{14} \gamma$-ray irradiation ${ }^{15}$ and ultraviolet radiation, ${ }^{\mathbf{1 6}}$ to improve interfacial adhesion of the material for broader industrial applications. The chemical treatments lowered the strength of ACFs to some extent because the fiber itself was damaged seriously, especially with oxidation methods and plasma treatment. ${ }^{17}$ Moreover, $\gamma$-ray irradiation and ultraviolet radiation were limited in practice due to highenergy consumption, high cost equipment and harsh reaction conditions in spite of preserving certain mechanical properties. Inspired by the sol-gel process of Stöber, ${ }^{18}$ a facile method was employed to modify ACFs with inorganic nano-materials.

Nowadays, versatile nanotechnology has attracted considerable attentions to develop new composites with desirable properties. ${ }^{19}$ The optimum use of nanoparticles in paper-based friction material is essential to obtain materials with excellent friction and wear properties. Low cost, widely abundance, high strength and stiffness and good wear resistance can be considered as the main reasons for using the nanosilica in the composites. $^{20,21}$ The direct addition of nanosilica to the friction material system was reported previously and it was limited by low retention of nanosilica in a wet-forming process. ${ }^{22,23}$ Thus the facile method of sol-gel synthesis of nanosilica on surface of ACFs was introduced in order to fabricate excellent paper-based friction material. Many attempts have been developed for the 
preparation of spherical silica particles via sol-gel process, ${ }^{\mathbf{2 4 - 2 7}}$ which has been widely used for the preparation of organicinorganic hybrid materials. ${ }^{28-30}$ This sol-gel process has such advantages of preserving strength and fiber structure ${ }^{31}$ and it can be easily implemented in the practical operation.

In this paper, $\mathrm{SiO}_{2}$ nanoparticles were in situ formed onto the $o$-ACFs via sol-gel method. The nanosilica-coated ACFs were used to prepare paper-based friction material. SEM, EDS and FT-IR were adopted to characterize the modified ACFs. The key parameters of paper-based friction materials, including dynamic friction coefficient, wear rate and the appearance of worn surfaces were all evaluated. At the same time, the application of sol-gel synthesis of nanosilica on surface of ACFs in the paper-based composite will be expanded.

\section{Experimental}

\subsection{Material}

Tetraethoxysilane (TEOS) (99.5\%), ammonia (25\%), ethanol (99.7\%) and phosphoric acid (PA) (85\%) were supplied by Tianjin Damao Chemical Reagent Company in China and used without further purification. Polyoxyethylene (PEO) $\left(M_{\mathrm{w}}=3 \times\right.$ $\left.10^{6}-4 \times 10^{6} \mathrm{~g} \mathrm{~mol}^{-1}\right)$ and cationic polyacrylamide (CPAM) $\left(M_{\mathrm{W}}\right.$ $\left.=5 \times 10^{6}-8 \times 10^{6} \mathrm{~g} \mathrm{~mol}^{-1}\right)$ were from Sumitomo Refining Co., Ltd., Japan. Two aramid fibers: para-aramid chopped fiber and para-aramid pulp, were produced by Hebei Silicon Valley Chemical Co., Ltd., China. Fillers, including sepiolite velvet, diatomite, alumina powder and the friction performance regulator such as graphite, were all used in the preparation of paperbased friction materials.

\subsection{In situ synthesis of $\mathrm{SiO}_{2}$ nanoparticles on surface of ACFs via sol-gel method}

para-Aramid chopped fiber was pretreated with phosphoric acid (PA) at a concentration of $20 \%$ to prepare oxidized aramid chopped fibers (o-ACFs) at $40{ }^{\circ} \mathrm{C}$ for $40 \mathrm{~min}$. The pretreated fiber was then thoroughly washed using cold deionized water until it was neutral, then filtered using polycarbonate membrane, and dried at $105^{\circ} \mathrm{C}$ for $4 \mathrm{~h}^{32,33}$ Nanosilica-coated ACFs were prepared through the sol-gel method as described in the previous work. ${ }^{34,35}$ Specifically, $o$-ACFs $(0.5 \mathrm{~g})$ were immersed in a mixture of ethanol $(50 \mathrm{~g})$, deionized water $(15 \mathrm{~g})$ and ammonium hydroxide $(6 \mathrm{~g})$, under moderate mechanical stirring followed by the addition of TEOS $(20 \mathrm{~g})$. The mixture was still held for $7 \mathrm{~h}$ with a constant stirring at $50{ }^{\circ} \mathrm{C}$. The resulting modified ACFs were collected by filtering and thoroughly washed with deionized water and then dried at $105{ }^{\circ} \mathrm{C}$ for $12 \mathrm{~h}$ in vacuum oven.

\subsection{Preparation of paper-based friction materials}

Paper-based friction materials were prepared by a wet-forming process to form a sheet with a quantitative weighing of $100 \mathrm{~g}$ $\mathrm{m}^{-2}$. The paper sheet was fabricated with a mixture of modified ACFs, aramid pulp and other fibers and fillers in a hand sheet former (TD10-200, Xianyang, China). The wet-forming process was as follows. First, the fibers and fillers were mixed and then separated into single fiber in water to form pulp suspension.
Subsequently, PEO used as dispersant and CPAM used as retention and drainage aid were added into the suspension. After stirring well in a pulp disintegrator (L\&W991509, Sweden), the pulp suspension was poured into the container of the handsheet former to drain thoroughly to form a wet paper sheet. The wet paper sheet was dried and then impregnated with resin using ethanol as solvent. After impregnation, the paper sheet was dried again in oven and hot-pressed by vulcanizing machine (Qingdao, China) at $150{ }^{\circ} \mathrm{C}$ for $2.5 \mathrm{~min}$ with pressure of $15 \mathrm{Mpa}$, resulting in the paper-based friction material. The control samples of paper-based friction materials were prepared by using the same process as above. The schematic illustration for preparing the paper-based friction material is shown in Fig. 1.

\subsection{Characterization and analysis}

The morphology of modified ACFs was observed by scanning electron microscope (SEM) (VEGA-3-SBH, Czech). The samples were sputtered with gold and observed with secondary electron imaging mode and an accelerating voltage of $3.0 \mathrm{kV}$. Energy dispersive spectroscopy (EDS) (Octane prime, the U.S.A.) was used to detect $\mathrm{SiO}_{2}$ nanoparticles on the surface of ACFs. Fourier transform infrared spectroscopy (FT-IR) (VECTOR22, German BRUKER Co.) was performed to characterize and compare the chemical structure of the modified ACFs and the pristine ACFs with a resolution of $4 \mathrm{~cm}^{-1}$ and a scanning range of 400-4000 $\mathrm{cm}^{-1}$. CFT-I multi-functional material surface performance tester (Lanzhou, China) was obtained to evaluate the friction and wear properties of the control sample (paperbased friction material containing pristine ACFs) and the modified sample (paper-based friction material containing modified ACFs) under a load of $100 \mathrm{~N}$ and a speed of $300 \mathrm{rpm}$. Additionally, the samples were required to be immersed in lubrication oil for $12 \mathrm{~h}$ before the friction and wear test.

\section{Results and discussion}

\subsection{Concept of nanosilica-coated ACFs preparation for improving their tribology properties in the preparation of friction materials}

Fig. 2 illustrated the concept of in situ synthesizing nanosilicacoated ACFs by sol-gel process. ACFs were pretreated by PA to achieve $o$-ACFs, which could introduce some hydroxyl groups and carboxylic groups on the surface. The $o$-ACFs were immersed and dispersed in a mixture of TEOS, ethanol, deionized water and ammonium hydroxide to obtain a stable and homogeneous suspension. Then, TEOS was hydrolyzed to yield silanol groups and silicon-oxygen bond. The condensation reaction of silanol groups generated silica through the condensation of $\mathrm{Si}-\mathrm{O}$ bond. The $\mathrm{SiO}_{2}$ nanoparticles were well established on the surface of ACFs with the connection of chemical bond (C-O-Si). Consequently, a silica layer was well coated at the surface of ACFs.

The proposed concept was based on:

(1) The mixture of ethanol, deionized water, ammonium hydroxide and added TEOS can be effectively reacted to 


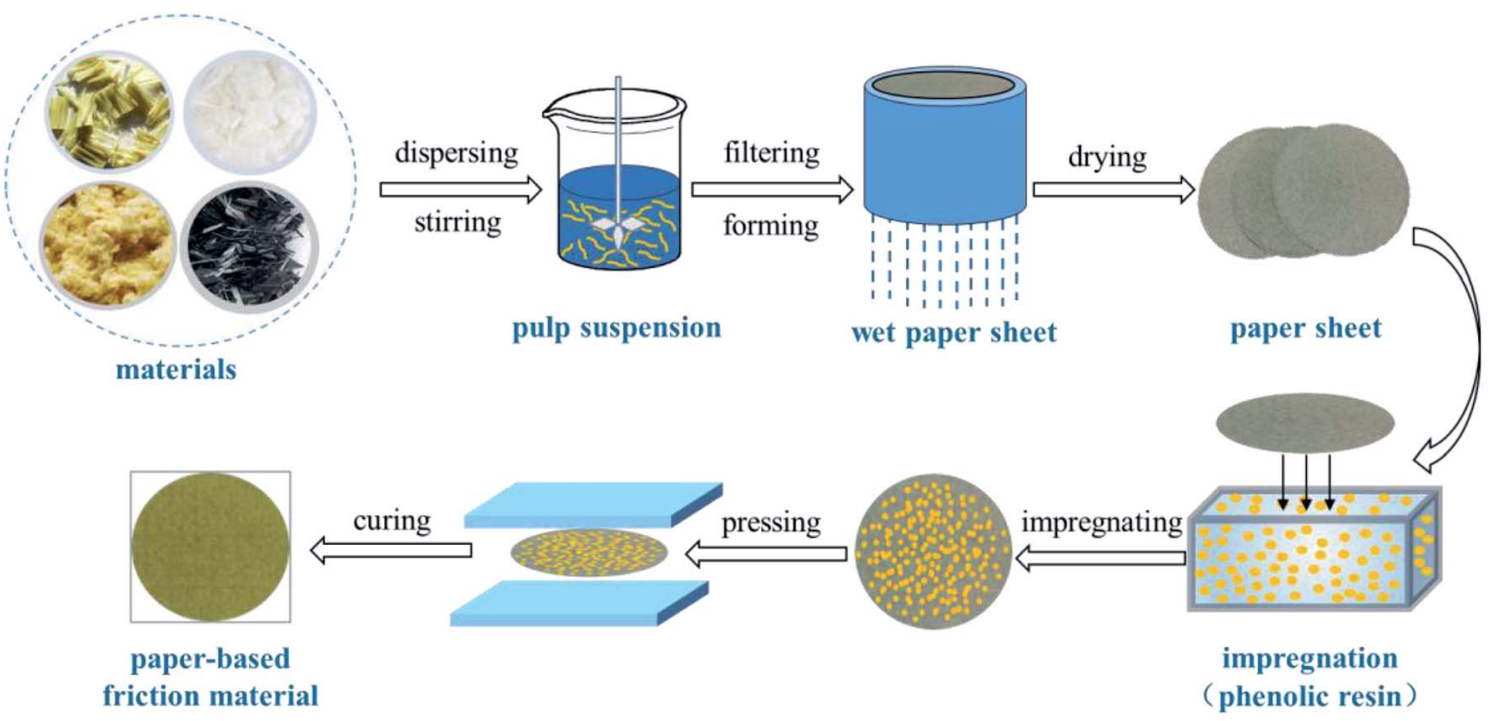

Fig. 1 Schematic illustration for preparing paper-based friction materials.

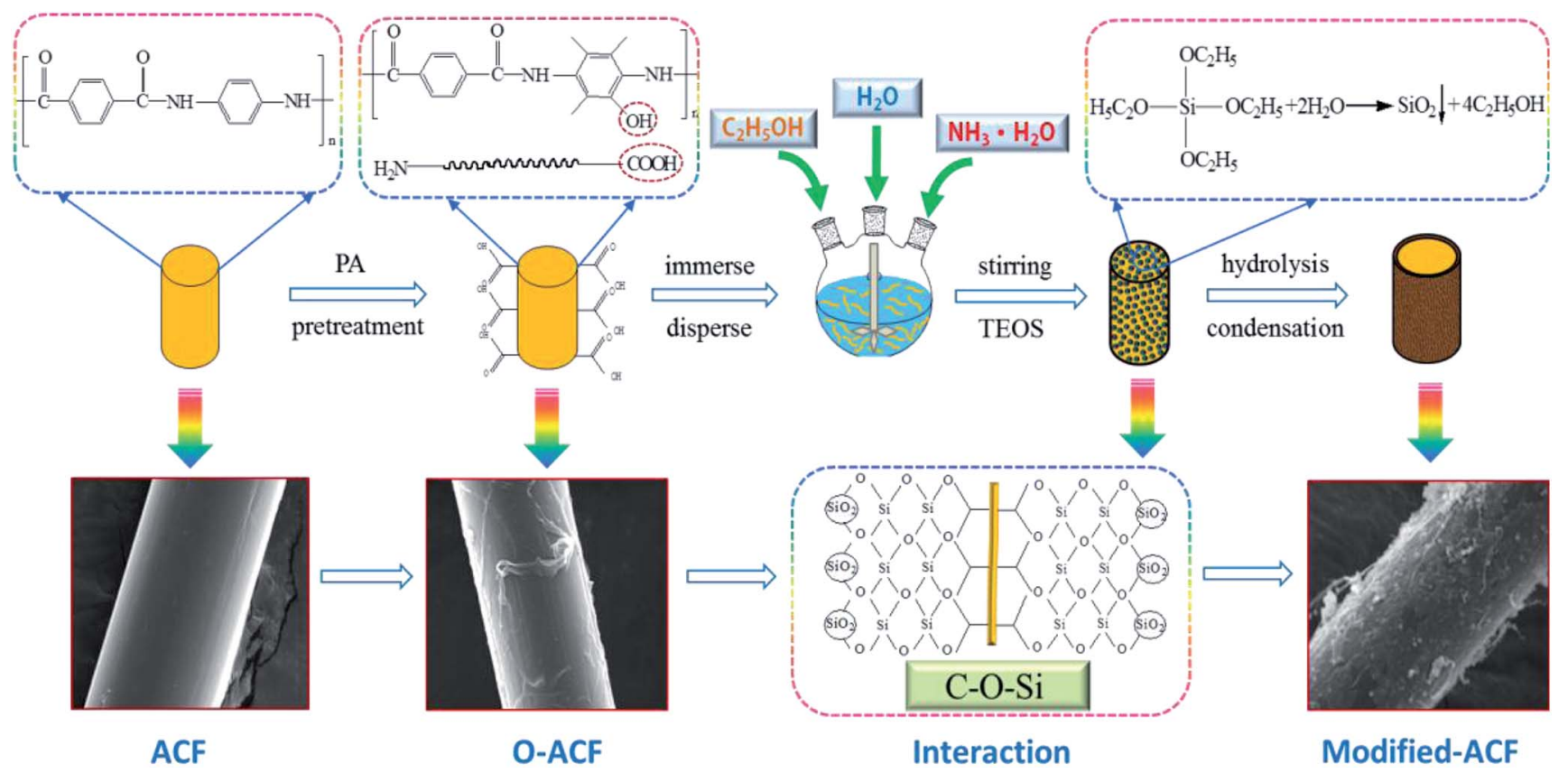

Fig. 2 Schematic illustration for preparing nanosilica-coated ACFs.

generate $\mathrm{SiO}_{2}$ nanoparticles, thus a coating layer of $\mathrm{SiO}_{2}$ nanoparticles were synthesized on the surface of $o$-ACFs.

(2) The $o$-ACFs could be sufficiently active to bond the silanol groups derived from the hydrolysis of precursor TEOS to fabricate nanosilica-coated ACFs with a concrete chemical bond (C-O-Si).

(3) The tribology properties of the modified sample could be improved through the modification of ACFs by in situ synthesis of $\mathrm{SiO}_{2}$ nanoparticles rather than the addition of nano-SiO the wet system, because the direct addition was limited by low retention of nanosilica in a wet-forming process, which made no sense to the properties of paper-based friction material.

\subsection{Characterizations of nanosilica-coated ACFs}

3.2.1 SEM analyses. Shown in Fig. 3 are the SEM results of the pristine ACFs and the modified ACFs. Fig. 3(c) and (f) showed the corresponding partial enlargements of Fig. 3(b) and (e), respectively. The pristine ACFs presented smooth surface shown in Fig. 3(a)-(c). The dense surface lattice, high axial orientation degree and rod-like structure of ACFs resulted in the smooth and chemically inert surface of fiber. ${ }^{36}$ After surface modification by sol-gel method, shown in Fig. 3(d)-(f), a dense coating was well distributed on the surface of ACFs and it was supposed to be $\mathrm{SiO}_{2}$ nanoparticles. The thickness of the coating 

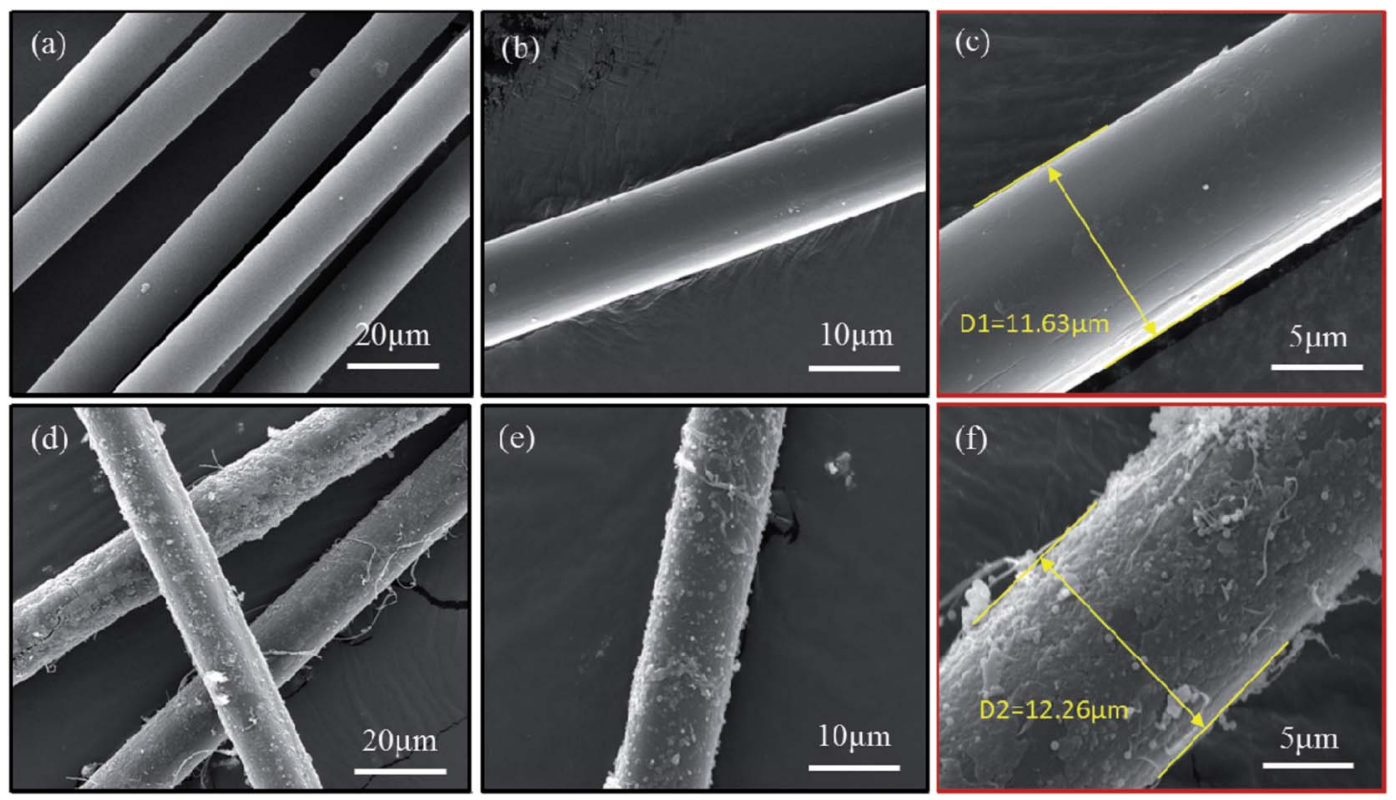

Fig. 3 SEM images of $(a-c)$ the pristine ACFs and $(d-f)$ the modified ACFs.

layer on the fiber was about $315 \mathrm{~nm}$ which could calculated from the diameter shown in Fig. 3(c) and (f). Therefore, the thickness of the nanosilica coating was hundreds of nanometers and the coating layer was just a single layer of nanosilica, which could validated from the fact that the nanosize of nanosilica remaining in suspension without the filtered fibers had been measured ranging from $300 \mathrm{~nm}$ to $500 \mathrm{~nm}$. This successful modification was probably ascribed to the hydrolysis of TEOS and subsequent condensation of $\mathrm{SiO}_{2}$ oligomer during the sol-gel process, ${ }^{37,38}$ which indicated the pretreatment of ACF with acid was essential for the growth of $\mathrm{SiO}_{2}$ nanoparticles on its surface. This was because the growth of $\mathrm{SiO}_{2}$ nanoparticles depended on strong chemical interactions between $\mathrm{SiO}_{2}$ oligomer and $o$-ACFs.

3.2.2 EDS analyses. EDS results of the pristine ACFs and modified ACFs showed successful deposition of $\mathrm{SiO}_{2}$ nanoparticles on the surface of ACFs, as observed in Fig. 4. From the figure, Si peak was remarkably intense in relation to the pristine ACFs. The change of $\mathrm{C}$ and $\mathrm{O}$ peaks was attributed to the acid treatment of ACFs and the growth of $\mathrm{SiO}_{2} \cdot{ }^{39}$ Additionally, Fig. 4 showed that modified ACFs consisted of carbon (39.25 wt\%), nitrogen (8.41 wt\%), oxygen (38.53 wt\%) and silicon (12.24 wt\%), whereas the pristine ACFs consisted of carbon (61.71 wt $\%)$, nitrogen (15.92 wt\%), oxygen (18.78 wt\%) and silicon (1.8 $\mathrm{wt} \%)$. The carbon and nitrogen content of the modified ACFs decreased, the oxygen and silicon content increased compared to the pristine ACFs. This result may be accounted for the following mechanisms. On the one hand, the decline of the carbon and nitrogen content was derived from the cleavage of amide bond (-CO-NH-) caused by PA pretreatment. On the other hand, the increase of oxygen and silicon content was ascribed to the generation of silicon-oxygen bond ( $\mathrm{Si}-\mathrm{O}-\mathrm{Si}$ ) caused by hydrolysis of TEOS precursor, which further proved the effective modification of ACFs with $\mathrm{SiO}_{2}$ nanoparticles. In spite of this, more evidences are required to further verify that this is not just a simple layer of physical coating.

3.2.3 FT-IR analyses. The FT-IR spectra of the pristine ACFs and modified ACFs are shown in Fig. 5 . The wide band between $3250 \mathrm{~cm}^{-1}$ and $3500 \mathrm{~cm}^{-1}$ after modification became stronger and wider, which was characteristic vibrations of active groups (such as $-\mathrm{NH},-\mathrm{OH}$ and $-\mathrm{C}=\mathrm{O}$ ) on the surface of modified ACFs. The peak between $1500 \mathrm{~cm}^{-1}$ and $1750 \mathrm{~cm}^{-1}$ was $\mathrm{C}=\mathrm{O}$ stretching vibration and $\mathrm{C}=\mathrm{C}$ framework vibration of benzene caused by amide I band, and the characteristic peak has been more intense after modification. The three significant typical bands near to $1100 \mathrm{~cm}^{-1}, 800 \mathrm{~cm}^{-1}$ and $450 \mathrm{~cm}^{-1}$ referred to chemical interface between $\mathrm{SiO}_{2}$ and ACFs, which were attributed to stretching vibration of $\mathrm{Si}-\mathrm{O}-\mathrm{C}, \mathrm{Si}-\mathrm{O}-\mathrm{Si}$ and $\mathrm{Si}-\mathrm{O}-\mathrm{Si}$,

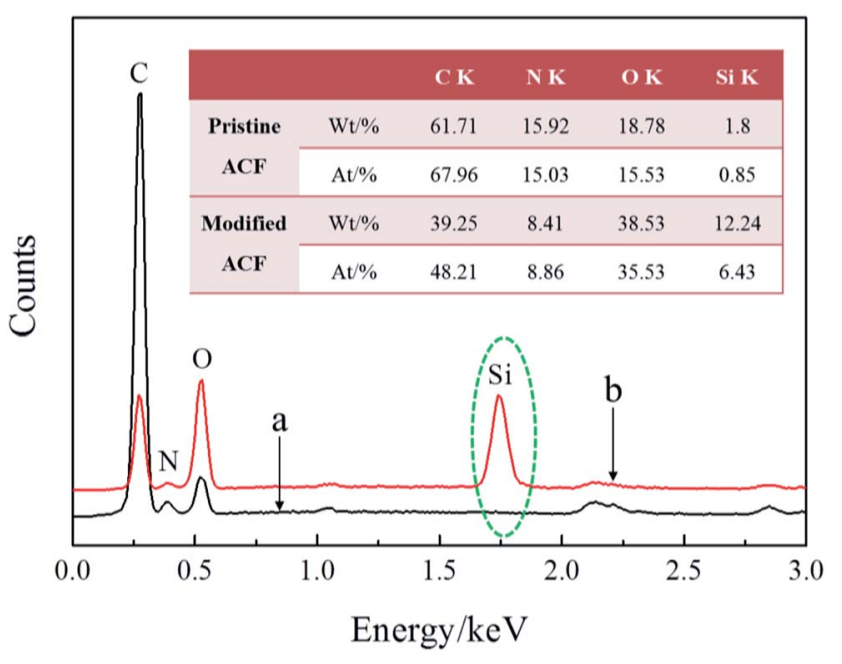

Fig. 4 EDS characterization of (a) the pristine ACFs and (b) the modified ACFs. 


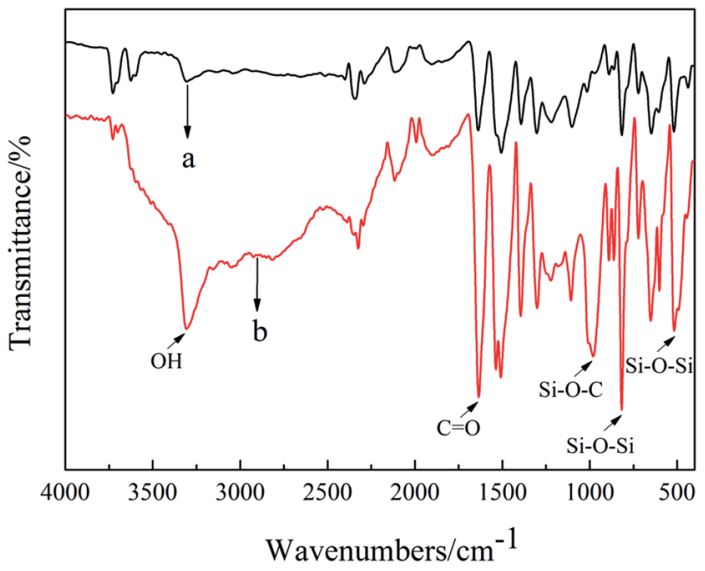

Fig. 5 FT-IR spectra of (a) the pristine ACFs and (b) the modified ACFs.

respectively. ${ }^{\mathbf{4 0 , 4 1}}$ The FT-IR spectra strongly confirmed that in the growth process of $\mathrm{SiO}_{2}$ nanoparticles, there was a concrete chemical bonding $(\mathrm{Si}-\mathrm{O}-\mathrm{C})$ between $\mathrm{o}$-ACFs and $\mathrm{SiO}_{2}$ nanoparticles, which differed from some physical coating tending to easily come off.

\subsection{Tribology properties}

3.3.1 Friction coefficient and stability. Shown in Fig. 6 are the results of dynamic friction coefficient $\left(\mu_{\mathrm{d}}\right)$ of the control sample (paper-based friction material containing pristine ACFs) and the modified sample (paper-based friction material containing modified ACFs) as a function of friction time. It was observed that $\mu_{\mathrm{d}}$ of the modified sample was apparently lower than the control sample. The lubrication oil was destroyed easily in more porous surface of the control sample leading to the higher $\mu_{\mathrm{d}}$. Otherwise, the $\mu_{\mathrm{d}}$ of both two samples showed a larger variation range during first 30 min showing the typical running-in stage characteristic, while the $\mu_{\mathrm{d}}$ showed a smaller variation after $30 \mathrm{~min}$, which was related to the change of friction surface. Moreover, both of two samples showed rising trend during the subsequent engagement time. The smaller the

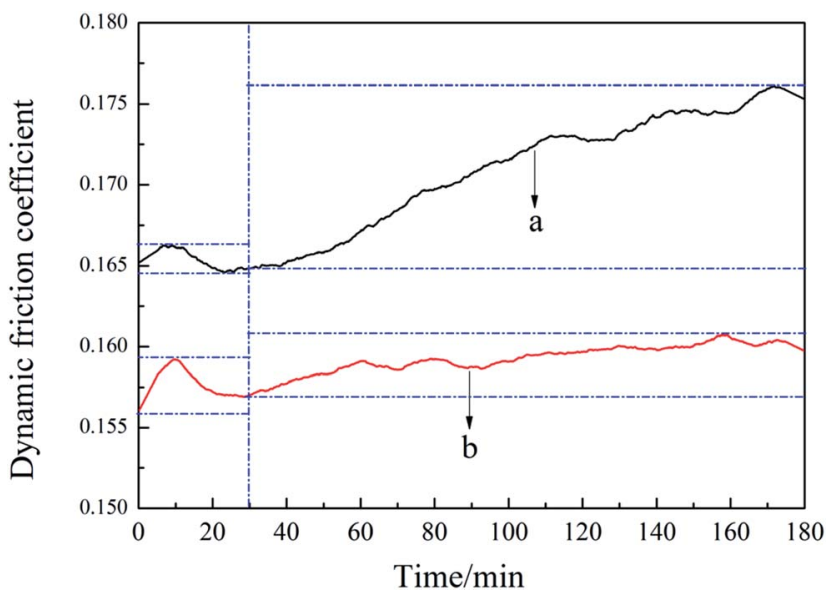

Fig. 6 Dynamic friction coefficients of (a) the control sample and (b) the modified sample. variation of $\mu_{\mathrm{d}}$ was, the better the friction stability was. ${ }^{1}$ It indicated that friction stability of modified sample was better than control sample in the late friction period, which meant modified ACF increased the stationarity of paper-based friction material. Moreover, nanosilica-coated ACFs resulted in the improvement of interfacial bonding strength of paper-based friction material, thus effectively decreasing the mechanical contact between asperities with the deformation of asperities. Under the joint action of modified ACFs and carbon fiber, the paper-based friction material could effectively prevent plastic flow of material caused by local overheat, thus eventually transforming sharp wear of friction material into the steady wear.

3.3.2 Wear rate and mechanistic analyses. The wear rate is one significant parameter for determining the service life of the paper-based friction material. The low wear rate leads to the long service life of friction material. The lower wear rate under the condition of high load and high temperature shows that material could work and function well under extreme conditions of heat and load.

Fig. 7 showed the wear rate of the pristine ACFs and modified ACFs in this contrast histogram. The wear rate of modified sample was significantly lower than the wear rate of the control sample with a decline of $30 \%$, which indicated the modified ACFs were beneficial to reduce the wear rate and alleviate the seriousness of the wear, and further illustrated the $\mathrm{SiO}_{2}$ nanoparticles possessed good wear resistance.

The explanation was as follows. In the friction process of paper-based friction material, with mechanical interlocking of asperities between friction pairs, the early dynamic friction coefficient was in a state of instant variation during the initial engagement. Subsequently, the lubrication oil could flow from the grooves and pores to the friction surface and eventually formed into oil film, ${ }^{\mathbf{4 2 - 4 4}}$ which transformed the touch between friction pairs into a touch between films. Generally this oil film had liquidity to reduce the interface shear stress and the friction coefficient for lubrication, ${ }^{45,46}$ especially for the modified sample with nanosilica-coated ACFs.

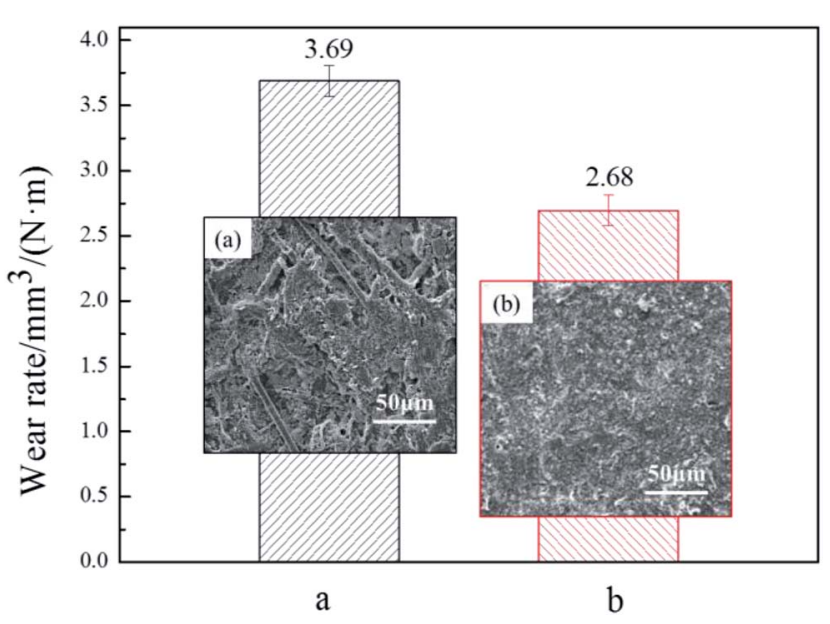

Fig. 7 Wear rate of (a) the control sample and (b) the modified sample. 
With an increment of friction time, the interface of the control sample would fracture when beyond a certain limit and the oil film was difficult to be formed on the rougher friction surface. Furthermore, the interfacial bonding between the substrate and reinforcement tended to be weak in the composite material system. The fibers were pulled out of the matrix with surrounding plastic deformation, thus producing more and more abrasive particles and debris. The wear loss and wear rate increased eventually. This result can be further supported by the SEM image in Fig. 7(a). It can be observed that more pores were appeared on worn surface after friction, which indicated the weaker adhesive force between fibers and resin matrix. However, the thermal degradation effect plays an important role in the major reason for higher wear rate. ${ }^{4-50}$ The porous structure of control sample could take away friction heat timely, which could effectively inhibit the thermal wear. Accordingly, the wear rate of control sample was just a little higher than the modified sample.

The modified samples with nanosilica-coated ACFs possessed good interfacial bonding strength and wear resistance properties because of $\mathrm{SiO}_{2}$ nanoparticles. ${ }^{51}$ The interface of the nanosilica-coated ACFs-containing sample would not easily fracture to cause the rupture of the interface because the modified ACFs enhanced the interfacial bonding strength of paper-based friction materials. All the components were closely interlaced under the adhesive of resin, thus less abrasive particles and lower wear loss remained on the worn surface, which were all presented in SEM image in Fig. 7(b).

The worn surfaces have great influence on the tribology properties of paper-based friction material. Indeed, strong wear appearing on the friction surface can be observed in order to discuss the effect of nanosilica modification of ACFs on the tribology properties. As expected, the SEM micrographs of unworn and worn surfaces of samples were shown in Fig. 8. It could be seen clearly that the worn surface of modified sample was much smoother than the control sample, which was related to the better wear resistance of modified sample.

Specifically, the Fig. 8(a) and (b) showed the unworn surface morphologies of the control sample. It could be seen each component of sample was smooth and flat, interlacing under the cladding of resin and bonding together with a resin binder and there appeared some pores on the surface of samples. Fig. 8(c) and (d) showed unworn surface morphologies of the modified sample. The small pores were almost filled with fine particles. All components of samples were more closely interlaced with adhesion of resin binder.

The worn surface morphologies of the control sample have been presented in Fig. 8(e) and (f). As shown in the figures, fibers and fillers on the surface of samples had obvious peeling traces after friction, strongly stripping with resin matrix. Broken fibers, cracks and pores were observed on the worn surface mainly because some fibers and fillers slipped and fractured under the condition of external force and high temperature. These broken and fractured compositions tended to be difficult to attach to the worn surface, even falling off due to their poor adhesion. Fig. $8(\mathrm{~g})$ and (h) showed the worn
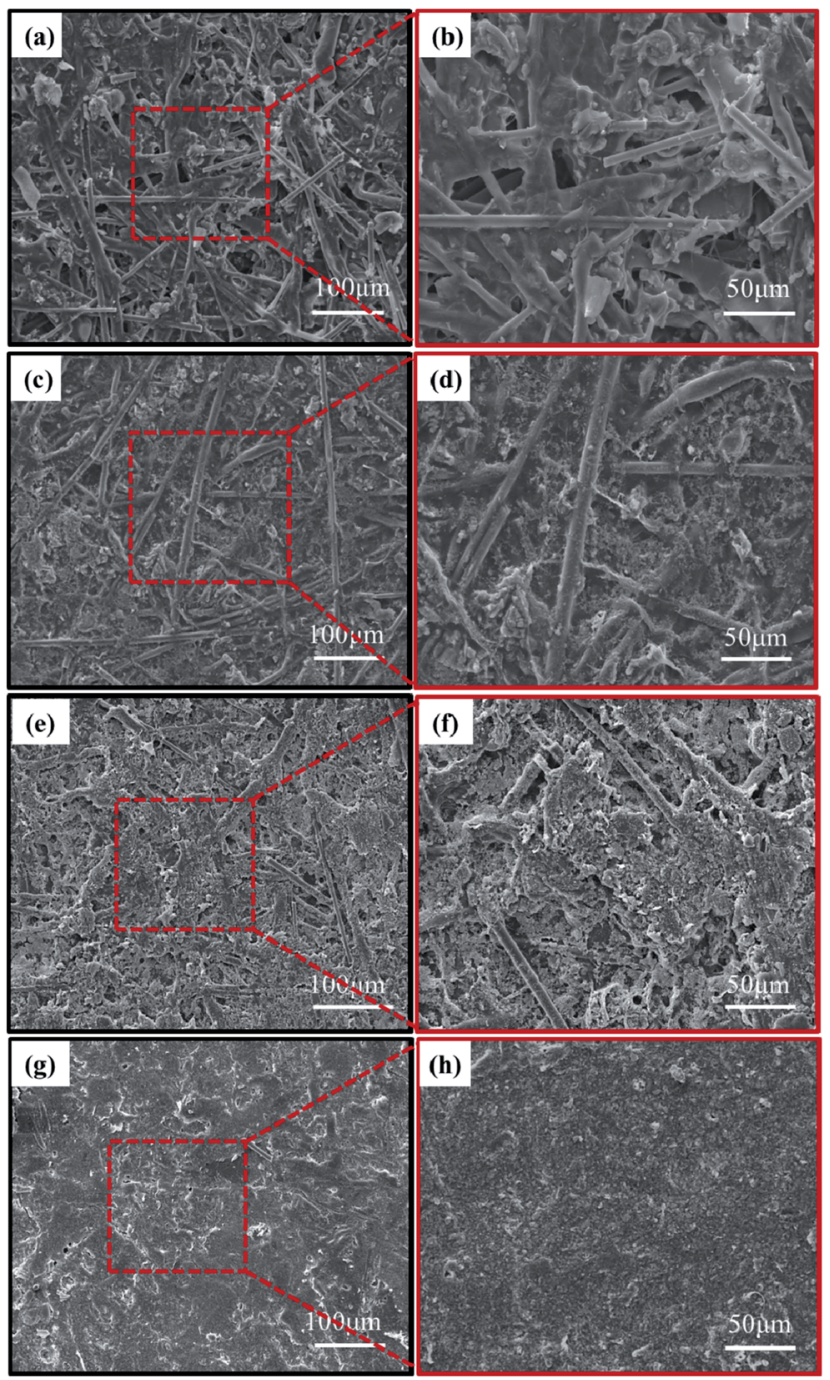

Fig. 8 The SEM micrographs of the unworn surface of ( $a$ and $b$ ) the control sample, (c and d) the modified sample and the worn surface of (e and $f$ ) the control sample, ( $g$ and $h$ ) the modified sample.

surface morphologies of the modified samples. It could be clearly seen there were fewer pitting and abrasive relatively, and the worn surface was smoother than the worn surface morphologies shown in Fig. 8(e) and (f). The fibers were gradually polished during engagement time and a smooth friction film was formed with a few tiny cracks and wear debris, which exhibited good wear resistance of modified sample. Moreover, the heat resistance and interfacial bonding of modified sample were improved, which could alleviate the peeling and embossment of asperities to form some fine abrasive particles. These particles were squeezed into the soft matrix because of friction heat under the press of rigid sliding friction block, which led to great deformation and stress in the contact area, and formed mild abrasive on the surface. Thus, the wear degree of the control sample was more serious than that of the modified sample, which was derived from that nanosilica-coated ACFs were beneficial to improve friction and wear properties of the materials. 


\section{Conclusions}

A facile sol-gel process has been successfully employed to modify ACFs with Si nano-particles; subsequently, the Si nanoparticle modified ACF was used to prepare paper-based friction materials based on a wet-forming process. The SEM and EDS results supported the conclusion that $\mathrm{SiO}_{2}$ nanoparticles were effectively deposited on the surface of ACFs. FT-IR analysis confirmed the formation of new chemical bond of $\mathrm{Si}-\mathrm{O}-\mathrm{C}$ between $\mathrm{SiO}_{2}$ and ACFs.

Furthermore, it was found that the tribology properties of paper-based friction materials containing modified ACFs were greatly improved in comparison with those from the pristine ACFs: the dynamic friction coefficient gradually reached a steady state as a function of time, and the wear rate decreased. The worn surface morphologies showed the wear degree of paper-based friction material with modified ACFs decreased compared to that with pristine ACFs.

\section{Acknowledgements}

The authors sincerely appreciated the financial support from the National Key Research and Development Plan (2016YFB0303304), Shaanxi Overall Planning Innovative Engineering Project of Science and Technology (2016KTCQ01-87) and Natural Science Research Start-up Fund of Shaanxi University of Science and Technology (2016GBJ-18).

\section{References}

1 J. Fei, H. K. Wang, J. F. Huang, X. R. Zeng and W. Luo, Tribol. Int., 2014, 72, 179-186.

2 T. Ai, R. M. Wang and W. Y. Zhou, Polym. Compos., 2010, 28, 412-416.

3 K. Goulouti, J. D. Castro and T. Keller, Compos. Struct., 2016, 136, 113-123.

4 H. J. Kong, C. Q. Teng, X. D. Liu, J. J. Zhou, H. P. Zhong, Y. Zhang, K. Q. Han and M. H. Yu, RSC Adv., 2014, 4, 20599-20604.

5 J. M. García, F. C. García, F. Serna and J. L. de la Peña, Prog. Polym. Sci., 2010, 35, 623-686.

6 S. H. Zhang, G. Q. He, G. Z. Liang, H. Cui, W. Zhang and B. Wang, Appl. Surf. Sci., 2010, 256, 2104-2109.

7 R. N. Sa, Y. Yan, Z. H. Wei, L. Q. Zhang, W. C. Wang and M. Tian, ACS Appl. Mater. Interfaces, 2014, 6, 21730-21738.

8 Z. Q. Lu, W. B. Dang, Y. S. Zhao, L. M. Wang, M. Y. Zhang and G. D. Liu, RSC Adv., 2017, 7, 7293-7302.

9 Z. Cheng, B. Y. Li, J. Y. Huang, T. Chen, Y. Liu, X. Wang and X. Y. Liu, Mater. Des., 2016, 106, 216-225.

10 T. K. Lin, S. J. Wu, J. G. Lai and S. S. Shyu, Compos. Sci. Technol., 2000, 60, 1873-1878.

11 C. Y. Yue, G. X. Sui and H. C. Looi, Compos. Sci. Technol., 2000, 60, 421-427.

12 C. X. Jia, P. Chen, W. Liu, B. Li and Q. Wang, Appl. Surf. Sci., 2011, 257, 4165-4170.

13 C. X. Wang, M. Du, J. C. Lv, Q. Q. Zhou, Y. Ren, G. L. Liu, D. W. Gao and L. M. Jin, Appl. Surf. Sci., 2015, 349, 333-342.
14 L. Liu, Y. D. Huang, Z. Q. Zhang, Z. X. Jiang and L. N. Wu, Appl. Surf. Sci., 2008, 254, 2594-2599.

15 Y. H. Zhang, Y. D. Huang, L. Liu and K. L. Cai, Appl. Surf. Sci., 2008, 254, 3153-3161.

16 L. Ghosh, M. H. Fadhilah, H. Kinoshita and N. Ohmae, Polymer, 2006, 47, 6836-6842.

17 Z. Cheng, B. Y. Li, J. Y. Huang, T. Chen, Y. Liu, X. Wang and X. Y. Liu, Mater. Des., 2016, 106, 216-225.

18 W. Stöber and A. Fink, J. Colloid Interface Sci., 1968, 26, 6269.

19 M. J. Sheykh, A. Tarmian, K. Doosthoseini and A. Abdulkhani, Polym. Bull., 2017, 1-11.

20 Q. Lin, G. Yang and J. Liu, Front Forest. China, 2006, 2, 230237.

21 Q. H. Zeng, A. B. Yu, G. Q. Lu and D. R. Paul, J. Nanosci. Nanotechnol., 2005, 5, 1574-1592.

22 H. Y. Jin, Y. Q. Wu, S. E. Hou, Y. L. Li, M. Liu, Z. J. Ji and J. Yuan, Tribol. Lett., 2013, 51, 65-72.

23 K. B. Sugozu, B. Daghan, A. Akdemir and N. Ataberk, Ind. Lubr. Tribol., 2016, 68, 259-266.

24 D. L. Green, J. S. Lin, Y. F. Lam, M. Z. C. Hu, D. W. Schaefer and M. T. Harrisf, J. Colloid Interface Sci., 2003, 266, 346-358.

25 X. D. Wang, Z. X. Shen, T. Sang, X. B. Cheng, M. F. Li, L. Y. Chen and Z. S. Wang, J. Colloid Interface Sci., 2010, 341, 23-29.

26 B. G. Trewyn, I. I. Slowing, S. Giri and S. Y. L. Victor, Acc. Chem. Res., 2007, 40, 846-853.

27 W. Cui, F. P. Du, J. C. Zhao, W. Zhang, Y. K. Yang, X. L. Xie and Y. W. Mai, Carbon, 2011, 49, 495-500.

28 N. Zheng, Y. D. Huang, W. F. Sun, X. S. Du, H. Y. Liu, M. Steven, J. F. Gao and Y. W. Mai, Carbon, 2016, 110, 69-78.

29 J. B. P. Ricardo, P. A. A. P. Marques, A. M. Barros-Timmons, T. Tito and P. N. Carlos, Compos. Sci. Technol., 2008, 68, 1088-1093.

30 X. J. Tian, G. H. Li, Z. Q. Tu, W. Yang, Y. F. Li, L. Q. Zhang, F. Yang and X. L. Jia, RSC Adv., 2016, 6, 597-600.

31 B. Mahltig, H. Haufe and H. Böttcher, J. Mater. Chem., 2005, 15, 4385-4398.

32 G. Li, C. Zhang, Y. Wang, P. Li, Y. H. Yu, X. L. Jia, H. Y. Liu, X. P. Yang, Z. M. Xue and S. K. Ryu, Compos. Sci. Technol., 2008, 68, 3208-3214.

33 L. Z. Sha and H. F. Zhao, Polymer, 2013, 37, 196-203.

34 Y. K. Yang, S. Q. Qiu, W. Cui, Q. Zhao, X. J. Cheng, K. Y. L. Robert, X. L. Xie and Y. W. Mai, J. Mater. Sci., 2009, 44, 4539-4545.

35 J. Raabe, A. D. S. Fonseca, L. Bufalino, C. Ribeiro, M. A. Martins, J. M. Marconcini and G. H. D. Tonoli, Carbohydr. Polym., 2014, 114, 424-431.

36 M. Xi, Y. L. Li, S. Y. Shang, D. H. Li, Y. X. Yin and X. Y. Dai, Surf. Coat. Technol., 2008, 202, 6029-6033.

37 B. P. Tripathi and V. K. Shahi, Prog. Polym. Sci., 2011, 36, 945-979.

38 K. Xie, Y. Yu and Y. Shi, Carbohydr. Polym., 2009, 78, 799805.

39 G. H. D. Tonoli, M. N. Belgacem, G. Siqueira, J. Bras, H. Savastano Jr and F. A. Rocco Lahr, Cem. Concr. Compos., 2013, 37, 68-75. 
40 T. J. Lu, M. Jiang, Z. G. Jiang, D. Hui, Z. Y. Wang and Z. W. Zhou, Composites, Part B, 2013, 51, 28-34.

41 M. Naghsh, M. Sadeghi, A. Moheb, M. P. Chenar and M. Mohagheghian, J. Membr. Sci., 2012, 423-424, 97-106.

42 M. Fesanghary and M. M. Khonsari, Tribol. Int., 2013, 67, 254-262.

43 M. Li, M. M. Khonsari and D. M. C. Mccarthy, Tribol. Int., 2014, 80, 222-233.

44 P. Payvar, Int. J. Heat Mass Transfer, 1991, 34, 1791-1798.

45 J. Fei, W. Luo, J. F. Huang, H. B. Ouyang, Z. W. Xu and C. Y. Yao, Tribol. Int., 2015, 87, 91-97.
46 R. Holinski and D. Hesse, Automob. Eng., 2003, 217, 765-770. 47 J. P. Li, S. H. Qi, J. Li, M. Y. Zhang and Z. F. Wang, RSC Adv., 2015, 5, 59398-59402.

48 A. L. Chaudhary, D. A. Sheppard, M. Paskevicius, M. Saundersc and C. E. Buckley, $R S C A d v$., 2014, 42, 21979-21983.

49 J. P. Li, S. H. Qi, J. Li, M. Y. Zhang and Z. F. Wang, J. Appl. Polym. Sci., 2015, 132, 42301-42306.

50 W. Y. Zhou, Y. Gong, L. T. Tu, L. Xu, W. Zhao, J. T. Cai, Y. T. Zhang and A. N. Zhou, J. Alloys Compd., 2017, 693, 1-8. 51 J. Y. Jang and M. M. Khonsari, J. Tribol., 1999, 121, 610-617. 